\title{
Biocompatibility of NiTi Alloy Implants in vivo
}

\author{
Gul Tosun, Emine Ünsaldi Latif Özler, Nuri Orhan, Ali Said Durmuş, and Hatice Eröksüz
}

\begin{abstract}
In this study, the powders of Ni and Ti with 50.5 at.\% $\mathrm{Ni}$ for $12 \mathrm{~h}$ were blended and cold pressed at the different pressures $(50,75$ and100 MPa).The porous product obtained after Ni-Ti compacts were synthesized by SHS (self-propagating hightemperature synthesis) in the different preheating temperatures $(200$, 250 and $300 \mathrm{oC})$ and heating rates $(30,60$ and $90 \mathrm{oC} / \mathrm{min})$. The effects of the pressure, preheating temperature and heating rate were investigated on biocompatibility in vivo. The porosity in the synthesized products was in the range of 50.7-59.7 vol. \%. The pressure, preheating temperature and heating rate were found to have an important effect on the biocompatibility in-vivo of the synthesized products. Max. fibrotic tissue within the porous implant was found in vivo periods (6 months), in which compacting pressure 100MPa.
\end{abstract}

Keywords-NiTi, biomaterial, SHS, biocompatibility.

\section{INTRODUCTION}

$\mathrm{N}$ ITI shape memory alloys (SMAs) are materials widely used in numerous biomedical applications (orthodontics, cardiovascular, orthopedics, urology, etc.) due to their good biocompatibility, unique shape memory properties, mechanical properties, superior damping capability, excellent corrosion resistance and wear resistance [1-8]. Since their mechanical properties are closer to those of cortical bones than stainless steels and titanium alloys [9], porous NiTi alloys show promising potential in the application of bone implantation. The porous structure also allows the ingrowths of new bone tissue along with the transport of body fluids, thus ensuring a harmonious bond between the implant and the body [4]. Measurements in literature suggests that NiTi alloy is safe and biocompatible due to its surface oxide film which is composed mainly of titanium oxide and acts as a barrier to prevent nickel from corrosion and ion leaching [10]. However, some negative side effects have been pointed out [9]. For example, the osteogenesis process and osteonectin synthesis activity in NiTi alloys are unfavorable compared to stainless steels and titanium alloys, Cell death rate is severe on NiTi alloys and proliferation of human gingival fibroblasts on NiTi samples with rough surface is slow compared to stainless steels and $\mathrm{Ti}$ alloys with the same surface roughness. The short-term biocompatibility of porous NiTi was determined to be comparable to that of dense NiTi. Moreover, in vivo standard allergy potential evaluation showed that porous NiTi

Gul Tosun and Nuri Orhan are wtih Firat University, Technology Faculty Metalurgy and Material Engineering Department, 23119 Elazig, Turkey

Hatice Eröksüz, Ali Said Durmuș, and Emine Ünsaldi are with Firat University, Faculty of Veterinary,23119 Elazig, Turkey edicine

Latif Özler is with Firat University, Technology Faculty, Mechanical Engineering Department, 23119 Elazig, Turkey has no potential to produce irritation, systemic toxicity reactions, or sensitization in animal models [11].

Porous NiTi SMAs have been fabricated with powder metallurgy (PM) processes such as self-propagating hightemperature synthesis (SHS), metal injection molding (MIP), hot isostatic pressing (HIP) and spark plasma sintering (SPS) $[4,5,12,13]$. These processes can avoid the problems associated with casting, like segregation or extensive grain growth and have the added advantages of precise control of composition and easy realization of complex part shapes [13]. The occurrence or amount of fibrosis inside the porous NiTi implant in bone tissue has not been assessed before. Rhalmi et al. [14] reported some fibroplasia and bone marrow within the pores of the porous NiTi implant.

The aim of this study was to find out the possible cytotoxic effects of NiTi implant material in vivo. NiTi implants with 50.5 at. \% $\mathrm{Ni}$ was fabricated by SHS at the different preheating temperatures, heating rates and pressures. The effects of the pressure and duration in vivo were investigated for the biocompatibility of implant material.

\section{MATERIAL AND METHOD}

\section{A. Experimental Procedure for Production}

Titanium and nickel powders were used to produce porous NiTi alloy implants. The raw materials were 325 mesh Titanium (99,5\% in wt.) and Nickel (99,8\% in wt.) powders. Characteristic features of powders used are given in Table I.

TABLE I

CHARACTERISTICS OF TI AND NI POWDERS [http://www.alfa-chemcat.com, 2007]

\begin{tabular}{|lll|}
\hline Feature of Material & Nickel & Titanium \\
Purity (\%) & 99.8 & 99.5 \\
Spesific gravitiy $(\mathrm{g} / \mathrm{mol})$ & 58,71 & 47,9 \\
Powder dimension $(\mathrm{mesh})$ & -325 & -325 \\
Melting heat $\left({ }^{\circ} \mathrm{C}\right)$ & 1453 & 1680 \\
Spesific weight $\left(\mathrm{g} / \mathrm{cm}^{3}\right)$ & 8,9 & 4,507 \\
Boiling heat $\left({ }^{\circ} \mathrm{C}\right)$ & 2832 & 3260 \\
\hline
\end{tabular}

The mixed powders of $\mathrm{Ni}$ and $\mathrm{Ti}$ with 50.5 at.\% Ni were blended for 12 hours and then cold pressed in a cylindrical die with $10 \mathrm{~mm}$ diameter under different compaction pressures using a hydraulic press. The cold compacted porous samples were heated under different heating rates with the protection of high purity argon gas $(99.9 \%)$ of about $0.1 \mathrm{MPa}$ in a furnace. The samples were ignited under different preheating temperatures using electrical discharge pulse $(14 \mathrm{kV}$ and 30 $\mathrm{mA}$ ). Once ignited, combustion waves could self-propagate along the axis to the other end of the compact in a very short time, and then porous NiTi implants were obtained by 
synthesizing. The procedure was repeated at different compaction pressures, preheating temperatures and heating rates to investigate the effects of these parameters on biocompatibility. The parameters used in the experiments are shown in Table II.

TABLE II

PARAMETERS USED AS VARIATION IN INVESTIGATE

\begin{tabular}{|l|l|}
\hline Parameters & Values \\
The compaction pressures (MPa) & $50,75,100$ \\
Preheating temperatures $\left({ }^{\circ} \mathrm{C}\right)$ & $200,250,300$ \\
Heating rates $\left({ }^{\circ} \mathrm{C} / \mathrm{min}\right)$ & $30,60,90$ \\
$\begin{array}{l}\text { Service period in vivo of the implants } \\
\text { (month) }\end{array}$ & $2,4,6$ \\
\hline
\end{tabular}

Thus biomaterial, both with high porosity and close to mechanical properties of the bone, was produced. The porosity (average void volume) of the implants was determined according to the formula was calculated by the following formulae:

$$
\varepsilon=\left(1-\frac{\rho}{\rho_{0}}\right) x 100
$$

where $\rho$ and $\rho_{0}$ are the density of the specimen and its corresponding theoretical density, respectively. The density of the specimen was determined by measuring its weight and dimension. The theoretical density of Ti-50.5 at.\% Ni alloy is $6.21 \mathrm{~g} / \mathrm{cm}^{3}$.

\section{B. Surgical Procedure}

The protocol of this study was reviewed and approved by the local ethics committee, in accordance with the Helsinki Declaration. The animal tests were performed after approval by the ethical committee of the University of Firat. Implantation of produced implants was performed in Firat University Veterinary Faculty Surgery Clinic.

Nine adult mongrel female clinically healthy dogs aged between 2 and 3-year-old (between 24-32 kg weight) were used in this study. The dogs were provided by Elazig Municipality, Turkey. The dogs were treated against antiparasite and vaccined. The animals were housed freely in three separate rooms, all cases were left free walk in the room and had free access to water and standard feed throughout follow up periods. Preoperatively the dogs were left hungry for 12 hours. General anaesthesia was induced in animals by intramuscular administration of combination of Xylazine hydrochloride $2 \mathrm{mg} / \mathrm{kg}$ (Rompun, Bayer, $23.32 \mathrm{mg} / \mathrm{ml}$ ), and ketamine hydrochlorur $15 \mathrm{mg} / \mathrm{kg}$ (Ketalar, Parke-Davis, 50 $\mathrm{mg} / \mathrm{ml})$.

Skin was incised along the medial side of the tibia. The skin incision extended from just proximal to the tibia to the distal end of the tibial crest. Subcutaneous tissues were incised on the same line and mobilized with the skin. Diaphysis of the radius was exposured by the conventional incision of subcutaneous fascia and muscles [15]. A $10 \times 15 \mathrm{~mm}$ defect was created in the metaphysis of the tibia.
The dogs were divided into three groups randomly and produced NiTi implants were implanted into the defect area. The first, second and third groups were transplanted produced by $50 \mathrm{MPa}, 75 \mathrm{MPa}$ and $100 \mathrm{MPa}$ implants respectively. Operation wound was closed by the conventional operational techniques. Postoperative medications included procaine peniciline G (22.000 IU/kg, IM, q $12 \mathrm{~h})$ administered for 5 days. Skin sutures were removed 10 days after the surgery.

Clinical evaluations were carried out at 30 days intervals. One dog in each group was sacrificed by overdose sodium penthobarbital at 2nd, 4th, and 6th months, and one dog in each group were harvested a piece of bone including implanted regions for histopathological examinations.

Histopathologic examinations were performed in the Pathology Laboratuary of Elazıg Harput Research and Application Hospital. The samples were placed in 10\% neutral buffered formalin immediately after reoperation. The section was fixed in $10 \%$ neutral buffered formalin for 5 days and decalcifed in $1 \%$ formic acide solution. The samples were cut into $5 \mu \mathrm{m}$ sections after complete decalcification and stained with hematoxylin and eosin (H\&E) and examined by light microscopy (Olympus BX51).

\section{RESULTS AND DISCUSSION}

$\mathrm{NiTi}$ alloys are used as biomaterials. Endurance and life of nitinol implants in vivo is still being studied and risk factor in utilization of this alloy in vivo is also unclear [16]. In this study, implant was produced at different preheating temperature, heating rate and pressure values.

It is seen that porosity is significant in bone-implant inerface at $250^{\circ} \mathrm{C}$ preheating temperautre and $60^{\circ} \mathrm{C} / \mathrm{min}$ heating rate (53-59\%) where the highest porosity among these implants is obtained [17]. This means that the best (threshold) production conditions were achieved by a preheating temperature of $250^{\circ} \mathrm{C}$, and a heating rate of $60^{\circ} \mathrm{C} / \mathrm{min}$. Therefore only the implants produced under these conditions and different compacting pressures $(50,75$ and $100 \mathrm{MPa})$ were implanted to the dogs and effort was paid to determine a relation between porosity and biocompatibility.

In the study conducted by Kujala et. al., the histological evaluation showed that the implants were well tolerated and the hard tissue preparations revealed, at the level of light microscopy, that bone grew into direct contact with the implant surface and into the void spaces inside the implant with all porosities [16].

Bone growth into porous metal surfaces depends on several factors, including the porosity of the surface, the stability and degree of micromotion between the implant and bone, whether the host bone is trabecular or cortical, and the presence of gaps between the implant and the bone surface [16]. In this paper, deformation of cells and infection was not observed in implants of all animals. This shows that the implant is well tolerated. The proper surgical procedure minimized the gapping and micromotion of the implant.

When two-month cases are examined,

In samples produced under $50 \mathrm{MPa}$ pressure, locally organized bone lamellae in this tissue were observed together 
with the formation of widespread granulation tissue. The surface of the implant is directly surrounded with new bone [18]. Direct bone connection is very important depending on the placement of the prosthesis for implant [19]. The expected bone response is the formation of fibrosis/fibroplasia followed by bone formation and maturation [18]. Increasing porosity helps bone ingress, which also helps body fluid flow through the pores with cappilary effect [19].

The formation of fibrous tissue (bone tissue) next to the young callus formation is observed in samples produced under $75 \mathrm{MPa}$ pressure (Fig. 1 (a)). The thickness of occurred fibrous tissue was measured as $0.1 \mathrm{~cm}$. Osteoblasts appears normal. In addition, active transformation of bone and osseointegration inside the pores of the implants was witnessed.

Bone tissue did not grow inside the pores and fibrosis capsule did not form in the implant fabricated by a compact pressure of $100 \mathrm{MPa}$. In addition, it was observed that the metal parts phagocytosed between trabecular bones and in free state. It was seen that bone tissue didn't have enough time to grow inside the pores because of low porosity.

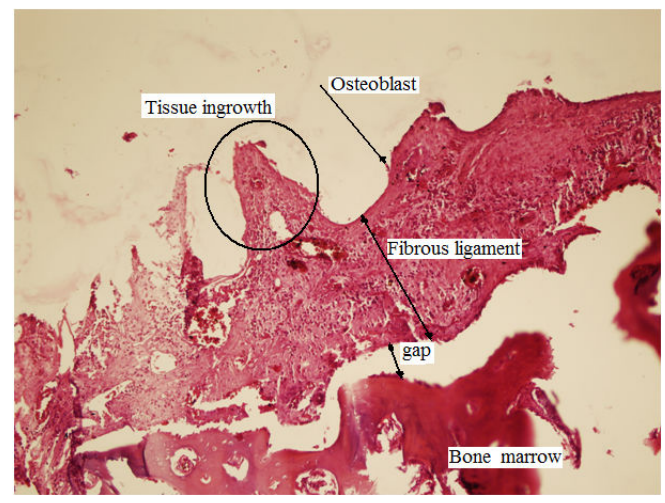

(a)

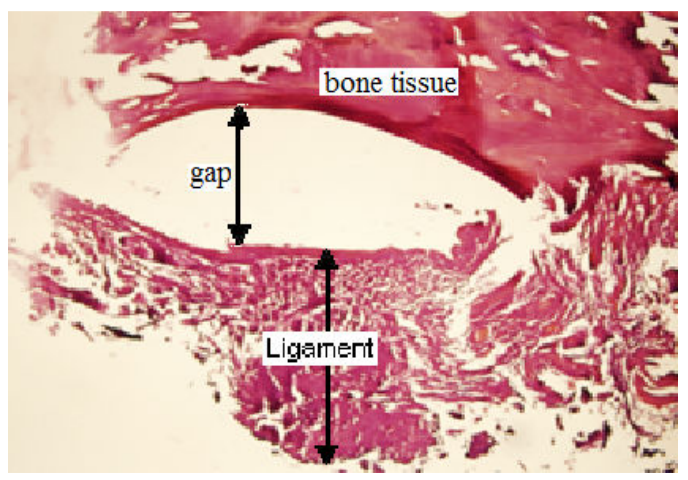

(b)

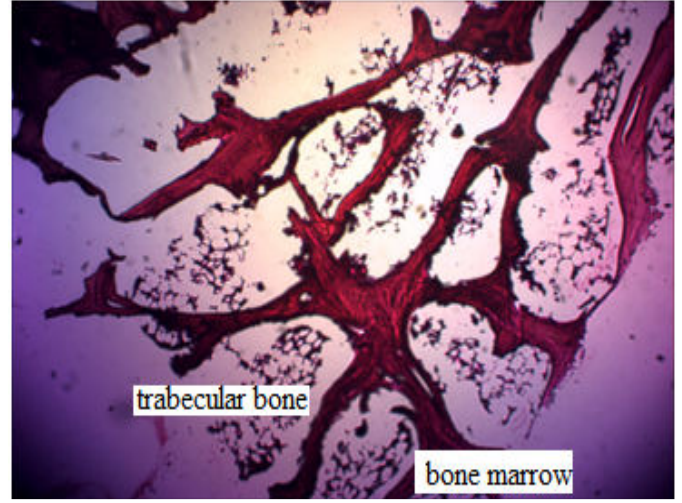

(c)

Fig. 1 Histopathologic appearence of a case of the 75MPa group HE x 10 a) At postoperative $2^{\text {nd }}$ month b) At postoperative $4^{\text {nd }}$ month c) At postoperative $6^{\text {nd }}$ month

When the vivo period of implant is increased as 4 months, it was observed that fibrous tissue was occurred at $50 \mathrm{MPa}$ produced samples with high porosity (Fig. 1 (b)). Metal residues were observed at $75 \mathrm{MPa}$ produced samples with lower porosity. The young callus formation was occurred at $100 \mathrm{MPa}$ produced samples with lowest porosity.

When six-month cases are examined, neither repair reactions were observed nor primary callus formed at $50 \mathrm{MPa}$ pressure produced samples. The granulation tissue (primary callus) formation wasn't observed at $75 \mathrm{MPa}$ pressure produced samples (Fig. 1 (c)). In addition, inflammatory reactions were not observed between the implant and the tissue. Common young granulation tissue and newly formed bone tissue were observed at 100MPa pressure produced samples.

Bone formation was only observed at $100 \mathrm{MPa}$ produced samples for 6 month in vivo period.

\section{CONCLUSION}

In this study biocompatibility of the implant from $\mathrm{NiTi}$ alloy was investigated. As a result the followings were concluded.

In 2 and 4-month period of in vivo implants made of pressure $50 \mathrm{MPa}, 2$-month period of in vivo implants made of pressure $75 \mathrm{MPa}$ and 4 and 6-month period of in vivo implants made of pressure $100 \mathrm{MPa}$, The developing reaction against implant in animal and reformed of bone tissue indicates that a good way of repair.

Especially for 2 months in vivo of implants made $75 \mathrm{MPa}$ pressure and for 4 months in vivo of implants made $50 \mathrm{MPa}$ was obtained best data that observed the fibrous tissue together with repair in implants.

6 months in vivo of implants made $50 \mathrm{MPa}$ and $75 \mathrm{Mpa}$ were occurred a bad way of repair.

Being in the cytoplasm of osteoblasts to have been phagocytosed and free in region of the metal particles on implant in animals associated with the duration of the experiment at 4-month in vivo period of implants made pressure of $75 \mathrm{MPa}$ and 2-month in vivo period implants made pressure $100 \mathrm{MPa}$ pressure. 


\section{ACKNOWLEDGMENT}

The authors would like to acknowledge the Firat University Scientific Research Projects Foundation (FUBAP-1137) for financial support for this study.

\section{REFERENCES}

[1] F. Sarsilmaz, N. Orhan, E. Unsaldi, A. S. Durmus, N.A. Colakoglu, A polyethylene-high proportion hydroxyapatite implant and its investigation in vivo Acta Bioeng Biomech, 9, 9-16, 2007.

[2] B.Y.Li, L. J. Rong, Y.Y. Li, V.E. Gjunter, Synthesis of porous Ni-Ti shape-memory alloys by self-propagating high temperature synthesis: reaction mechanism and anısotropy in pore structure, Acta Mater, 48, 3895-904, 2000.

[3] A. Michiardi, C .Aparicio, J.A. Planell, F.J. Gil, Electrochemical behaviour of oxidized NiTi shape memory alloys for biomedical applications. Surf Coat Tech. 201,6484-8, 2007.

[4] C.L. Yeh, W.Y. Sung, Synthesis of NiTi intermetallics by selfpropagating combustion, J Alloy Compd, 376, 79-88, 2004.

[5] C.L. Chu, C.Y. Chung, P.H. Lin, S.D. Wang Fabrication of porous NiTi shape memory alloy for hard tissue implants by combustion synthesis, Mat Sci Eng A-Struct., 366,114-9, 2004.

[6] B.Y. Li, L.J. Rong, Y.Y. Li, Stres-strain behavior of porous Ni-Ti shape memory intermetallics synthesized from powder sintering, Intermetallics, 8, 643-6, 2000.

[7] D. Bogdanski, M. Koller, D. Muller, G. Muhr, M Bram, H.P. Buchkremer et al. Easy assessment of the biocompatibility of Ni-Ti alloys by in vitro cell culture experiments on a functionally graded $\mathrm{Ni}$ NiTi-Ti material. Biomaterials, 23, 4549-4555, 2002.

[8] A. Kapanen, J. Ilvesaro, A. Danilov, J. Ryhanen, P. Lehenkari, J. Tuukkanen, Behaviour of Nitinol in osteoblast-like ROS-17 cell cultures. Biomaterials, 23, 645-650, 2002.

[9] P.K. Chu, Bioactivity of plasma implanted biomaterials Nucl Instrum Meth B, 24, 1-7, 2006.

[10] C.Y. Li, X.J. Yang, L.Y. Zhang, M. F. Chen, Z. D. Cui, In vivo histological evaluation of bioactive NiTi alloy after two years implantation, Mat Sci Eng C-Bio S, 27, 122-126, 2007.

[11] A. Bansiddhi, T.D. Sargeant, S.I. Stupp, D.C. Dunand, Porous NiTi for bone implants: A review, Acta Biomater, 4, 773-82, 2008

[12] A. Biswas, Porous NiTi by thermal explosion mode of SHS: processing, mechanism and generation of single phase microstructure, Acta Mater, 53, 1415-1425, 2005.

[13] C. Shearwood, Y.Q. Fu, L. Yu, K.A. Khor, Spark plasma sintering of TiNi nano-powder, Scripta Mater, 52, 455-60, 2005.

[14] S. Rhalmi, M. Odin, M. Assad, M. Tabrizian, C.H. Rivard, L.H. Yahia, Hard. soft tissue and in vitro cell response to porous nickel- titanium: a biocompatibility evaluation Biomed Mater Eng, 9, 151-62, 1999.

[15] T. Duerig, A. Pelton, D. Stockel, An overview of nitinol medical applications Mat Sci Eng A-Struct, 273-275, 149-60, 1999.

[16] G. Tosun, L. Ozler, M. Kaya, N. Orhan, A study on microstructure and porosity of NiTi alloy implants produced by SHS, J Alloys Comp, 487, 605-611, 2009.

[17] D.A. Armitage, T.L. Parker, D.M. Grant, Biocompatibility and hemocompatibility of surface-modified NiTi alloys J Biomed Mater Res A, 66, 129-37, 2003

[18] M.F. Chen, X.J. Yang, R.X. Hu, Z.D. Cui, H.C. Man, Bioactive NiTi shape memory alloy used as bone bonding implants, Mater. Sci. Eng. C, 24, 497, 2004.

[19] S.L. Zhu, X. J. Yang, M.F. Chen, C.Y. Li, Z.D. Cui, Effect of porous NiTi alloy on bone formation: A comparative investigation with bulk NiTi alloy for 15 weeks in vivo, Mat Sci Eng, 28, 1271-1275, 2008. 